\title{
Vibrational Analysis of Azacrown Ether Complex with Li Metal Cation
}

\author{
Kyung-Chul Min, Sun-Kyung Park, Choongkeun Lee, Chang Suk Kim, ${ }^{\dagger}$ and Nam-Soo Lee ${ }^{*}$ \\ Department of Chemistry, Chungbuk National University, Cheongju, Chungbuk 361-763, Korea \\ ${ }^{*}$ E-mail: nslee@chungbuk.ac.kr \\ ${ }^{\dagger}$ Department of Chemistry Education, Chungbuk National University, Cheongju, Chungbuk 361-763, Korea \\ Received August 24, 2010, Accepted October 18, 2010
}

\begin{abstract}
$\mathrm{Li}^{+}$ion complex of azacrown ether with restricted motion of freedom and pseudo-bilateral symmetry was studied by infrared spectroscopy, which has shown simplified and broadened vibrational features. The $\mathrm{C}=\mathrm{O}$ and $\mathrm{N}-\mathrm{H}$ stretching bands, in particular, shows anomalous broadening nearly $\sim 150 \mathrm{~cm}^{-1}$. The density functional calculation at the level of BP86/6-31+G** shows that $\mathrm{Li}^{+}$ion is trapped and rather free to move around inside the cavity, as much as about $0.70 \AA$. Through the relocation of $\mathrm{Li}^{+}$ion inside the cavity, the conformational changes would occur rapidly in its symmetry $C_{1} \rightleftarrows C_{2} \rightleftarrows C_{1}$. The potential barrier was obtained to be merely $\sim 2.2 \mathrm{~kJ} / \mathrm{mol}$ for $C_{1} \rightarrow C_{2}$. During this conformational alteration, the amide backbone twists concurrently its dihedral angle side to side about up to \pm 3 degree. Selected vibrational modes were interpreted in terms of the force constant variations of local symmetry coordinates between conformations in the framework of $C_{1} \rightleftarrows C_{2} \rightleftarrows C_{1}$.
\end{abstract}

Key Words: Azacrown ether, Li metal cation complex, Vibrational analysis, Dynamic effects

\section{Introduction}

Crown ether species have drawn considerable attention because of their binding selectivity with alkali metal cations, ${ }^{1-4}$ $\mathrm{Li}^{+}, \mathrm{Na}^{+}, \mathrm{K}^{+}, \mathrm{Rb}^{+}$and $\mathrm{Cs}^{+}$, with alkaline-earth metal cations, ${ }^{4,5}$ with heavy metal ions, ${ }^{4,6}$ or organic functional groups. ${ }^{7,8}$ To understand the nature of crown ether-metal cation complexes, the spectroscopic or theoretical studies of complexes in the gas phase, solid phase and solution have been performed in the scope of the coordination structures and conformations. The 18-crown- 6 backbone has been most studied partly because it is quite flexible and prone to various conformations of symmetry upon complex formation. ${ }^{3}$ It is known to form open structures to host the heavier alkali cations, such as $\mathrm{Rb}^{+}$or $\mathrm{Cs}^{+}$, and to adopt folded cage-like conformations for the lighter alkali cations, $\mathrm{Li}^{+}$or $\mathrm{Na}^{+}$. The infrared spectra of these alkali complexes of 18-crown-6 backbone show some peculiarities, for example, continuum features in the mid range of 1500 to $3500 \mathrm{~cm}^{-1}$ or in the far-infrared range, and line broadening or coalescing features of specific infrared absorption bands. ${ }^{2}$ Sometimes it experiences a significant enhancement of infrared activity. Some of the infrared bands were not seen at all, partly because of extremely weak intensity, or heavily broadened, especially, in the crown- $\mathrm{Li}^{+}$complex. These features were often understood to demonstrate complete complex formation. The 12-crown-4 complexes with alkali metal ions do not show apparently these odd features in the infrared spectra, however. ${ }^{9}$ It could be primarily due to the smaller cavity size and restricted flexibility of the undersized cyclic system.

Concerning a line broadening in infrared absorption, various chemical systems were rationalized in the context of dynamic processes, e.g., conformational changes or chemical exchanges. For mixed-valence pyrazine-bridged complex system of Os or $\mathrm{Ru}$ cation, a strong vibronic coupling between ligand vibrations and low-lying electronic transitions, as well an electronic de- localization through vibrationally coupled fast intra-molecular electron exchange were regarded for causing life-time broadening. ${ }^{10-13}$ Vibrational coupling responsible for broadening could occur between symmetric groups spatially nearby in the singlewell potential surface. ${ }^{14}$ Moreover, the out-of-phase modes in two halves of a molecule could couple vibrationally each other for intensity enhancing. Then the charge oscillation between two halves increases strongly to generate higher dipole moment changes, consequently to produce an enhanced intensity. For alkali metal cation-crown ether complex system, the multiminima potential surface with low barriers was utilized which could be comprehended within the fast exchange phenomena, also.

In the present study, infrared spectrum in the solid phase of azacrown ether complex with $\mathrm{Li}^{+}$ion was studied by the vibrational analysis. This azacrown ether had shown its potential interest as selective complexing agent which has two amide groups replacing oxygen atoms, a pyridine group replacing an oxygen atom, and two benzo groups as parts of skeletal backbone. This species showed good complexation capability with smaller van der Waals radius $\mathrm{Li}^{+}$, comparable to larger $\mathrm{K}^{+}$and $\mathrm{Rb}^{+} .^{15,16}$ It has more rigid skeletal structure and much less flexibility in the cyclic system, but similar or a little larger cavity size to usual 18 -crown- 6 backbone. We are trying to elucidate the nature of $\mathrm{Li}^{+}$ion complex as well the effects on infrared spectrum induced from the complex formation, which system has considerably restricted motion of freedom and less symmetric divergence in the molecular structure, not likely to usual 18-crown-6 backbone.

\section{Experimental and Computation Methods}

Azacrown ether adopted in this work, [5,6,14,15-dibenzo2,18-pyridino-4,16-diazo-7,10,13-trioxocyclooctadecan-3,17dione] was synthesized as described elsewhere. ${ }^{15}$ Complex with 
$\mathrm{Li}^{+}$ion was prepared using $\mathrm{LiClO}_{4}$ in $N, N$-dimethylformamide and dried in vacuum. The infrared spectrum was obtained using the Bruker IFS66 spectrometer with DTGS detector, Nernst bar light source and $\mathrm{KBr}$ beam splitter in the spectral resolution of $4 \mathrm{~cm}^{-1}$ and 100 times accumulation for each run. Calculations were performed at the theory level of BP86 using 6-31+G** basis set with the Gaussian03 program package (Gaussian, Inc.). The isotope atomic masses adapted for calculations were 12.01115 for carbon, 14.00307 for nitrogen, 15.9994 for oxygen, and 1.007825 for hydrogen, respectively. The temperature was set to $298.15 \mathrm{~K}$ and the pressure to $1.0 \mathrm{~atm}$.

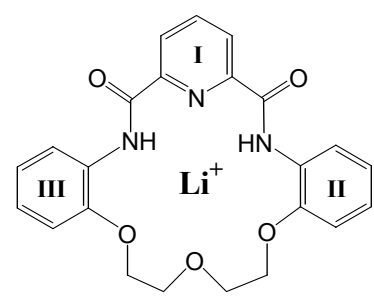

Azacrown ether employed has 52 atoms and the local symmetry coordinates ( $C_{2}$ point group) were composed of 55 stretching, 91 in-plane bending, 21 out-of-plane deformation, and 32 torsion modes. Molecular geometry for each species under consideration was fully optimized to get vibrational frequencies of normal modes and Cartesian coordinate force field. The force constants matrix in the Cartesian coordinate generated through density functional calculation has 12246 elements for azacrown ether and 12720 elements for $\mathrm{Li}^{+}$ion-azacrown ether complex which are composed of all the diagonal and half the off-diagonal elements. The Cartesian coordinate force field was converted to internal coordinate force field to acquire the force constants of the local symmetry coordinates, the frequencies, and potential energy distributions using Wilson's GF matrix method. All the procedures including composition of internal coordinates and local symmetry coordinates were described in detail elsewhere. ${ }^{17}$

\section{Results and Discussion}

The experimentally observed infrared spectra of pure azacrown ether and its $\mathrm{Li}^{+}$complex in the solid phase are shown in Figure 1. For the complex, it displays widely broadened bands and as well several relatively narrow bands. Also, it shows some extent of continuum feature in the 500 to $2000 \mathrm{~cm}^{-1}$ range. Furthermore, its spectroscopic feature is much simpler than that of the pure azacrown ether because many bands are missing or barely seen, in particular, in mid infrared range. The calculated infrared harmonic spectra without applying scale factor at the level of BP86/6-31+G** theory are displayed in Figure 2, where the pure azacrown ether ( $C_{2}$ symmetry), two analogues, Right $\left(C_{1}\right.$ symmetry, where $\mathrm{Li}^{+}$ion slightly $(\sim 0.35 \AA)$ right from the near principal axis) and $\operatorname{Left}\left(C_{1}\right.$ symmetry, where slightly $(\sim 0.38 \AA)$ left) and a complex with $\mathrm{Li}^{+}$ion $\left(C_{2}\right.$ symmetry, where $\mathrm{Li}^{+}$ion is positioned on the principal axis). The infrared spectra of Left and Right look almost the same, so only one is displayed.

The $\mathrm{Li}^{+}$ion complex with $C_{2}$ symmetry has one imaginary frequency from calculation representing a transition state (TS). Each of other three structures does not show any imaginary

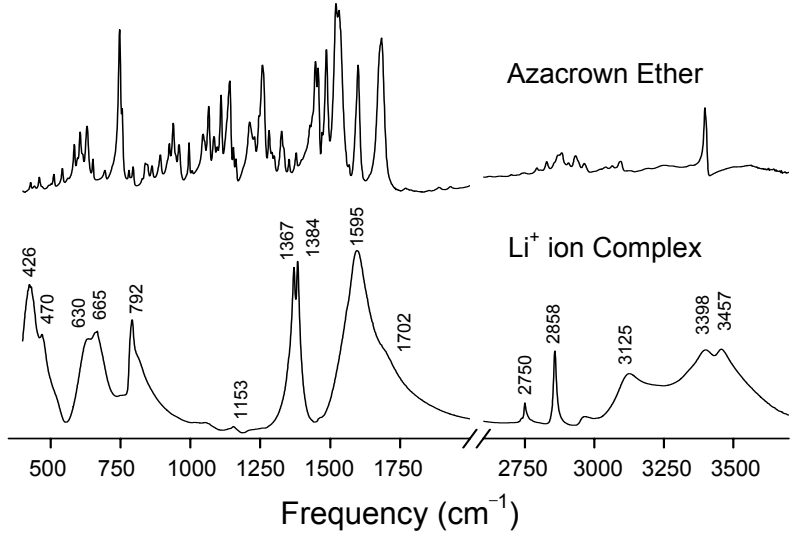

Figure 1. Experimentally observed infrared spectra of Azacrown Ether (Top) and its $\mathrm{Li}^{+}$ion Complex (Bottom) in the solid phase.

frequencies representing each local minimum in the potential surface. Left or Right species represents a little distorted or deformed from $T S$ species upon $\mathrm{Li}^{+}$ion movement (left or right, back or forth, up or down) inside the cavity. Considering a condensed phase, the contributions of rotational and translational entropy to total entropy were ignored for the total free energy correction. ${ }^{14}$ Therefore the vibrational entropy was only counted to obtain the Gibbs free energy change. The stabilization free energies upon complex formation were obtained for three different geometries nearly $260 \sim 270 \mathrm{~kJ} / \mathrm{mol}$ as shown in Table 1 . The energy barrier between Left (or Right) and TS species is just about $\sim 2.2 \mathrm{~kJ} / \mathrm{mol}$ less than the thermal energy unit $k_{B} T, \sim 2.5$ $\mathrm{kJ} / \mathrm{mol}$ at ambient temperature. This indicates that the potential surface for $\mathrm{Li}^{+}$ion movement has the shape of $\mathrm{W}$ with very low energy barrier between two local minima. Therefore, $\mathrm{Li}^{+}$ion which is trapped inside the cavity can move around readily at least $\sim 0.35 \AA$ across the potential barrier. This is consistent to previous assertion, a large polarizability of $\mathrm{Li}^{+}$ion in various crown ether complexes. ${ }^{2}$ Nonetheless, this complex may be considered either as a mixture of assorted conformers because $\mathrm{Li}^{+}$ ion shuffles on the multi-minima potential surface with low potential barriers (i.e., wide and shallow).

The conformational changes on the $\mathrm{Li}^{+}$ion movement could be realized by DA (dihedral angle) between structural groups as shown in Table 1. DA between two benzo groups (Ring II and Ring III in the figure above) remains almost steady at $56 \sim 57^{\circ}$ for three different geometries. DA between pyridyl group (Ring I above) and a plane containing central ether linkage C-O-C moiety also does change a bit or much less than others for three geometries. In contrast, DA between Ring I and II or Ring I and III alters about $\pm 7^{\circ}$ from the $T S$ species, $27.5^{\circ}$. This demonstrates that the pyridyl group turns a small piece couterclockwise or clockwise along the principal axis accompanied with about $\pm 3^{\circ}$ distortion of amide backbones. Two ethylene groups on both sides of oxygen atom in central ether linkage also twist in accordance with pyridyl group, but in the opposite phase. Consequently, upon $\mathrm{Li}^{+}$ion motion, the central part of the complex including pyridyl group, two amide backbones and two ethylene groups shows winding and unwinding motions while the angle between two benzo groups is kept constant almost not moving. Accordingly, the structural adjustment upon $\mathrm{Li}^{+}$ion dislocation 
Table 1. Energetics of azacrown ether and three different geometries of $\mathrm{Li}^{+}$- azacrown ether complex, and the dihedral angles between structural groups. The bold faced numbers in Dihedral Angle section indicate nearly constant dihedral angles between interconnected planes.

\begin{tabular}{|c|c|c|c|c|c|c|}
\hline \multirow{2}{*}{\multicolumn{2}{|c|}{$\mathrm{BP} 86 / 6-31+\mathrm{G}^{* *}$}} & \multirow{2}{*}{$\mathrm{Li}^{+}$} & \multirow{2}{*}{ Azacrown Ether, $C_{2}$} & \multicolumn{3}{|c|}{$\mathrm{Li}^{+}$- Azacrown Ether Complex } \\
\hline & & & & $T S, C_{2}$ & Left, $C_{1}$ & Right, $C_{1}$ \\
\hline \multicolumn{2}{|c|}{$\varepsilon_{0}$, Electronic Energy $(\mathrm{Eh})$} & -7.27494 & -1429.56697 & -1436.94273 & -1436.94307 & -1436.94307 \\
\hline \multicolumn{2}{|c|}{ Zero Point Energy Corrected (Eh) } & -7.27494 & -1429.16797 & -1436.54121 & -1436.54137 & -1436.54136 \\
\hline \multicolumn{2}{|c|}{ E, Thermal Energy Corrected (Eh) } & -7.27353 & -1429.14160 & -1436.51395 & -1436.51349 & -1436.51349 \\
\hline \multicolumn{2}{|c|}{ H, Thermal Enthalpy Corrected (Eh) } & -7.27258 & -1429.14066 & -1436.51301 & -1436.51255 & -1436.51254 \\
\hline \multicolumn{2}{|c|}{ G, Thermal(vibrational) Free Energy Corrected (Eh) } & -7.27258 & -1429.18686 & -1436.56066 & -1436.56151 & -1436.56152 \\
\hline \multicolumn{2}{|c|}{$\begin{array}{l}\Delta \mathrm{G}, \text { Stabilization Free Energy upon complex } \\
\text { formation }(\mathrm{kJ} / \mathrm{mol})\end{array}$} & 0 & 0 & -265.76 & -267.99 & -268.00 \\
\hline \multicolumn{4}{|c|}{$\Delta(\Delta \mathrm{G})$, Free Energy Difference $(\mathrm{kJ} / \mathrm{mol})$} & $\mathbf{0}$ & -2.23 & -2.24 \\
\hline \multirow{7}{*}{ Dihedral Angle } & Ring I and Ring II & & $27.4^{\circ}$ & $27.5^{\circ}$ & $34.9^{\circ}$ & $21.4^{\mathrm{o}}$ \\
\hline & Ring I and Ring III & & $27.4^{\circ}$ & $27.5^{\circ}$ & $21.2^{\circ}$ & $34.5^{\circ}$ \\
\hline & Ring II and Ring III & & $49.7^{\circ}$ & $56.1^{\circ}$ & $57.3^{\circ}$ & $57.1^{\circ}$ \\
\hline & $\begin{array}{l}\text { Ring I and Plane containing } \\
\text { central ether linkage C-O-C }\end{array}$ & & $124.1^{\circ}$ & $106.0^{\circ}$ & $107.5^{\circ}$ & $107.5^{\circ}$ \\
\hline & Amide backbone C-C-N-C & & $176.2^{\circ}$ & $180.0^{\circ}$ & $-176.3^{\circ}$ & $177.3^{\circ}$ \\
\hline & Ethylene bridge(1) O-C-C-O & & $50.9^{\circ}$ & $49.0^{\circ}$ & $48.3^{\circ}$ & $53.5^{\circ}$ \\
\hline & Ethylene bridge(2) O-C-C-O & & $50.9^{\circ}$ & $49.0^{\circ}$ & $53.7^{\circ}$ & $48.2^{\circ}$ \\
\hline
\end{tabular}

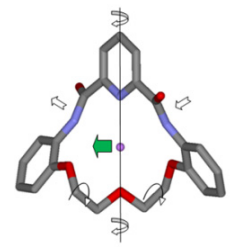

Left

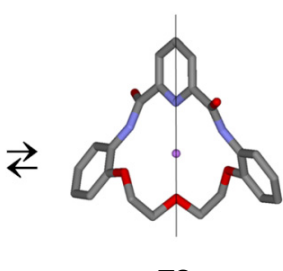

TS

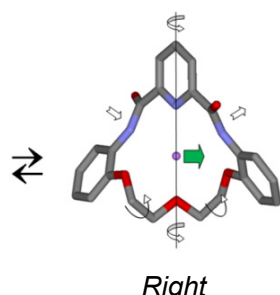

Right
Scheme 1

can be illustrated as following Scheme 1. The positional displacement of $\mathrm{Li}^{+}$ion and turning angles of other moieties are exaggerated for clarity. The relative angular and positional displacements are very diminutive as shown in Table 1 .

Diagonal force constants of selected local symmetry coordinates for pure azacrown ether and three different $\mathrm{Li}^{+}$complexes obtained at BP86/6-31+G** force field are shown in Table 2. In the right column, the variations of force constants between Left and Right species are listed in the form of $\delta(R \sim L)=100 \times$ $\left|f_{R}-f_{L}\right| /\left(f_{R}+f_{L}\right) / 2$, and the variations of the average of Left and Right species from transition state $T S$ species in $\delta(R L \sim T S)=$ $100 \times \operatorname{SQRT}\left(\left(\left(f_{R}-f_{T S}\right)^{2}+\left(f_{L}-f_{T S}\right)^{2}\right) / 2\right) /\left(f_{R}+f_{L}\right) / 2$, respectively. In the complex, if three force constants are similar each other for a certain coordinate $(\delta(R \sim L) \approx 0$ and $\delta(R L \sim T S) \approx 0)$, one could assume that it would give a distinct band (possibly a doublet for W-shaped potential curve with low barrier) corresponding to its transition dipole change. When the force constant of $T S$ species is far dissimilar to those of Left or Right species $(\delta$ $(R \sim L) \approx 0$ and $\delta(R L \sim T S)>>0)$, it would be broaden to show very wide bandwidth or could show a continuum background implicating continuous alteration of force constants. On the other hand, if there is enough dissimilarity among three force constants $(\delta(R \sim L)>>0$ and $\delta(R L \sim T S)>>0)$, it would not be seen in spectral feature because the force constant of that coordinate keeps unsteady through continuous conformational adjustment caused by restless relocation of $\mathrm{Li}^{+}$ion trapped inside

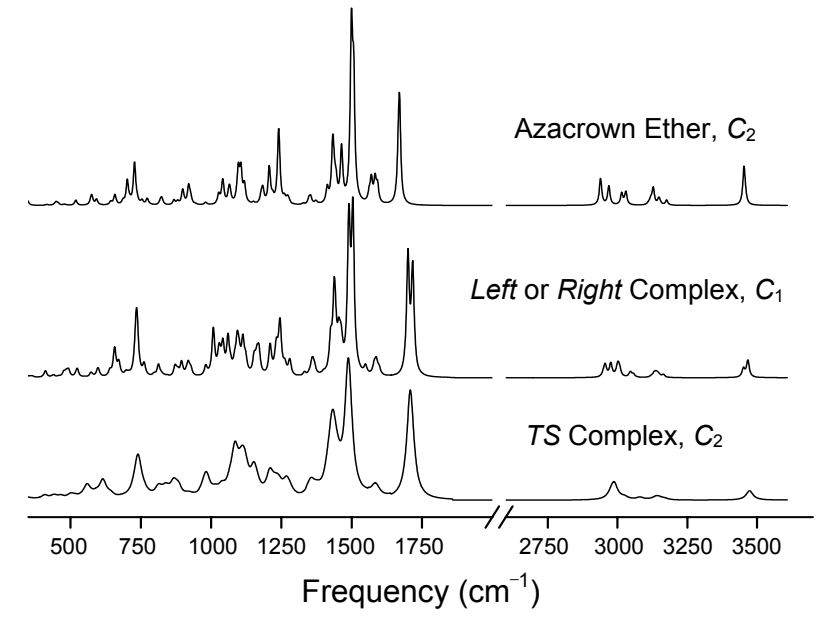

Figure 2. Calculated infrared harmonic spectra (not scaled) at the level of BP86/6-31+G** theory. (Top: Azacrown Ether; $C_{2}$, Middle: Left or Right; $C_{1}$ (where $\mathrm{Li}^{+}$ion is placed slightly $(\sim 0.38 \AA$ ) left or slightly $(\sim 0.35 \AA)$ right from the near principal axis, respectively. Only one is shown because both spectra appear virtually the same.), Bottom: $\mathrm{Li}^{+}$ion-Azacrown Ether Complex; Transition State(TS), $C_{2}$.

the cavity.

Vibrational feature of calculated infrared spectrum (Top in Figure 2) for azacrown ether is very alike to experimentally obtained (Top in Figure 1), almost every peak matching one-to-one far to $750 \mathrm{~cm}^{-1}$ region. Diagonal force constants of azacrown ether listed in left column of Table 2 are quite comparable to the system of 4,13-diaza-18-crown-6 previously reported. ${ }^{18,19}$ As distinguished from azacrown ether, obviously not for the complex partly because the calculation of a formula representing a complex does not operate for any dynamic effects induced from the conformational changes. Other system was reported to show an interaction between $\mathrm{Li}^{+}$ion and $\pi$-electrons. ${ }^{20}$ Because $\mathrm{Li}^{+}$ ion has relatively small van der Waals radius $\left(\mathrm{Li}^{+} ; 0.68 \AA, \mathrm{Na}^{+}\right.$; $0.97 \AA, \mathrm{K}^{+} ; 1.33 \AA, \mathrm{Rb}^{+} ; 1.47 \AA, \mathrm{Cs}^{+} ; 1.67 \AA$ ) and it is placed in- 
Table 2. Diagonal force constants of selected local symmetry coordinates for azacrown ether and three different geometries of $\mathrm{Li}^{+}$- azacrown ether complex, and the force constant variations between $\mathrm{Li}^{+}$- azacrown ether complexes; TS = transition state, $\delta(R \sim L)=100 \times\left|f_{R}-f_{L}\right| /\left(f_{R}+\right.$ $\left.f_{L}\right) / 2$ and $\delta(R L \sim T S)=100 \times \operatorname{SQRT}\left(\left(\left(f_{R}-f_{T S}\right)^{2}+\left(f_{L}-f_{T S}\right)^{2}\right) / 2\right) /\left(f_{R}+f_{L}\right) / 2$. The bold faced numbers represent low variation in force constants.

\begin{tabular}{|c|c|c|c|c|c|c|c|}
\hline \multirow{3}{*}{ BP86/6-31+G** } & \multirow{3}{*}{ Local Symmetry Coordinate } & \multicolumn{4}{|c|}{ Diagonal Force Constant } & \multirow{2}{*}{\multicolumn{2}{|c|}{ Force Constant Variation, $\%$}} \\
\hline & & \multirow{2}{*}{$\begin{array}{c}\text { Azacrown } \\
\text { Ether } \\
C_{2}\end{array}$} & \multicolumn{3}{|c|}{$\mathrm{Li}^{+}$- Azacrown Ether Complex } & & \\
\hline & & & $\begin{array}{l}\boldsymbol{T S} \\
C_{2} \\
\end{array}$ & $\begin{array}{c}\text { Left } \\
C_{1}\end{array}$ & $\begin{array}{c}\text { Right } \\
C_{1}\end{array}$ & $\delta(R \sim L)$ & $\delta(R L \sim T S)$ \\
\hline \multirow{9}{*}{$\begin{array}{l}\text { Streching } \\
(\mathrm{mdyn} / \AA)\end{array}$} & N-H (amide) & 6.5666 & 6.6877 & 6.5666 & 6.5663 & 0.00 & 1.85 \\
\hline & $\mathrm{C}=\mathrm{O}$ (amide) & 10.9433 & 11.6096 & 10.9439 & 10.9440 & 0.00 & 6.08 \\
\hline & C-H (pyridyl) & 5.3410 & 5.3928 & 5.3443 & 5.3411 & 0.06 & 0.94 \\
\hline & C-H (benzo) & 5.3500 & 5.3991 & 5.3496 & 5.3501 & 0.01 & 0.92 \\
\hline & C-H (methylene) & 5.0133 & 5.0632 & 5.0124 & 5.0119 & 0.01 & 1.02 \\
\hline & $\mathrm{C} \sim \mathrm{C}$ (pyridyl) & 7.7023 & 6.9932 & 7.0737 & 7.0713 & 0.03 & 1.12 \\
\hline & $\mathrm{C} \sim \mathrm{C}$ (benzo) & 6.8451 & 6.8578 & 6.8457 & 6.8457 & 0.00 & 0.18 \\
\hline & C-C (ethylene bridge) & 4.1943 & 4.3369 & 4.1994 & 4.1948 & 0.11 & 3.33 \\
\hline & $\mathrm{C}-\mathrm{O}$ (ether linkage) & 4.7416 & 4.7088 & 4.8157 & 4.7804 & 0.74 & 1.90 \\
\hline \multirow{4}{*}{$\begin{array}{c}\text { Methylene } \\
\text { Deformation } \\
\text { in ethylene bridge } \\
\left(\mathrm{mdyn} \AA / \mathrm{rad}^{2}\right)\end{array}$} & $\mathrm{CH}_{2}$ (scissoring) & 0.5818 & 0.5841 & 0.5827 & $\mathbf{0 . 5 8 3 5}$ & 0.14 & 0.18 \\
\hline & $\mathrm{CH}_{2}$ (wagging) & 0.7145 & 0.7148 & 0.7142 & 0.7121 & 0.29 & 0.27 \\
\hline & $\mathrm{CH}_{2}$ (twisting) & 0.8998 & 0.9521 & 0.8686 & 0.9364 & 7.51 & 6.66 \\
\hline & $\mathrm{CH}_{2}$ (rocking) & 1.2694 & 1.1693 & 1.0825 & 1.0455 & 3.48 & 10.05 \\
\hline \multirow{5}{*}{$\begin{array}{c}\text { In-plane } \\
\text { Deformation } \\
\left(\text { mdyn } \AA / \mathrm{rad}^{2}\right)\end{array}$} & $\mathrm{C} \sim \mathrm{N} \sim \mathrm{C}$ (pyridyl) & 6.7708 & 4.3532 & 6.9071 & 6.9145 & 0.11 & 37.01 \\
\hline & $\mathrm{C} \sim \mathrm{C} \sim \mathrm{C}$ (benzo) & 3.6670 & 3.9166 & 3.3900 & 3.3865 & 0.10 & 15.59 \\
\hline & C-O-C (ether linkage) & 1.0687 & 1.4922 & 1.2185 & 1.3122 & 7.41 & 18.31 \\
\hline & N-H (amide) & 0.5300 & 0.5665 & 0.5369 & 0.5365 & 0.07 & 5.55 \\
\hline & $\mathrm{C}=\mathrm{O}$ (amide) & 2.9957 & 1.8066 & 3.0001 & 2.9834 & 0.56 & 39.61 \\
\hline \multirow{4}{*}{$\begin{array}{l}\text { Out-of-plane } \\
\text { Deformation } \\
\left(\operatorname{mdyn} \AA / \mathrm{rad}^{2}\right)\end{array}$} & N-H (amide) & 0.1054 & 0.1147 & 0.1048 & 0.1054 & 0.57 & 9.14 \\
\hline & $\mathrm{C}=\mathrm{O}$ (amide) & 0.6697 & 0.7933 & 0.6984 & 0.7114 & 1.84 & 12.57 \\
\hline & C-H (pyridyl) & 0.3035 & 0.3060 & 0.3038 & $\mathbf{0 . 3 0 3 7}$ & 0.03 & 0.74 \\
\hline & C-H (benzo) & 0.3613 & 0.3788 & 0.3671 & 0.3687 & 0.43 & 2.97 \\
\hline \multirow{4}{*}{$\begin{array}{c}\text { Torsion } \\
\left(\operatorname{mdyn} \AA / \operatorname{rad}^{2}\right)\end{array}$} & $\mathrm{C} \sim \mathrm{C}$ (pyridyl) & 0.5772 & 0.6179 & 0.5782 & 0.5778 & 0.07 & 6.90 \\
\hline & $\mathrm{C} \sim \mathrm{C}$ (benzo) & 0.7217 & 0.7062 & 0.7204 & 0.7263 & 0.82 & 2.41 \\
\hline & C-C (ethylene bridge) & 2.4853 & 3.7864 & 2.2596 & 2.8706 & 23.82 & 49.08 \\
\hline & C-N (amide backbone) & 0.6168 & 0.9408 & 0.6339 & 0.6847 & 7.71 & 42.87 \\
\hline
\end{tabular}

side cavity distant from $\pi$-electrons, it is more realistic to assume any conformational alterations rather than $\pi$-interaction.

Most of the normal modes of macrocyclic system like 18crown- 6 backbone are complicatedly associated (or mixed) with numerous internal coordinates in the system, mostly because of its high degrees of freedom in the structural motion due to flexibility of the macrocyclic system. In Table 2, the local symmetry coordinates are divided into several blocks, e.g., stretching, deformation (methylene, in-plane and out-of-plane bending), and torsion.

Stretching. The diagonal force constants of stretching coordinates were almost the same or similar to each other between Left and Right species except C-O stretching in central ether linkage. The $\mathrm{N}-\mathrm{H}$ and $\mathrm{C}=\mathrm{O}$ in amide, $\mathrm{C}-\mathrm{C}$ and $\mathrm{C}-\mathrm{O}$ stretching coordinates in the ethylene ether moiety are fairly dispersed as shown in $\delta(R L \sim T S)$. Ring $\mathrm{C} \sim \mathrm{C}$ stretching modes of pyridyl groups and $\mathrm{C}-\mathrm{H}$ stretching coordinates of ethylene, pyridyl, and benzo groups are moderately dispersed. The N-H coordinate shows extremely broad $\left(\mathrm{HWHH}=\sim 150 \mathrm{~cm}^{-1}\right.$ ) feature with huge wings spanning both sides of two peaks at 3398 and $3457 \mathrm{~cm}^{-1}$, and its wavelength is similar to that of pure azacrown ether, 3400 $\mathrm{cm}^{-1}$ as displayed in Figure 1. This remarkable broadening of $\mathrm{N}-\mathrm{H}$ stretching is quite surprising because it is demanding to pull out any instructive information from vibrational analysis. According to above remarks, the amide backbone is forced to fluctuate continuously up and down, i.e., very similar to the puckering motion (e.g., $\mathrm{NH}_{3}$ in gas phase) as displayed in above Scheme 1. Consequently, it could be understood that the intramolecular structural alteration would affect the vibrational relaxation time to be longer in shallow multi-minima potential surface with low barriers. The $\mathrm{C}=\mathrm{O}$ coordinate shows also extraordinarily broad feature which can be seen as a band at about $\sim 1700 \mathrm{~cm}^{-1}$ with wide wings. The $\mathrm{C}=\mathrm{O}$ stretching could be treated in the same way because it is experiencing equivalent environments to neighboring $\mathrm{N}-\mathrm{H}$ bond. In contrast to $\mathrm{C}=\mathrm{O}$ or $\mathrm{N}-\mathrm{H}$, the $\mathrm{C}-\mathrm{H}$ stretching of ethylene bridge gives two relatively narrow peaks at 2750 and $2858 \mathrm{~cm}^{-1}$ and $\mathrm{C}-\mathrm{H}$ stretching of pyridyl and benzo shows moderately broad bunches at near 3125 $\mathrm{cm}^{-1}$ overlapped on a wing of N-H stretching bands. Ring C $\sim \mathrm{C}$ stretching modes of pyridyl and benzo groups shows a broad band together near at $\sim 1585 \mathrm{~cm}^{-1}$ overlapped with $\mathrm{C}=\mathrm{O}$ stretching bands. These are generally consistent with the variations 
of diagonal force constants listed in Table 2. The skeletal C-O, C-N, and C-C stretching coordinates usually spread in $800 \sim$ $1200 \mathrm{~cm}^{-1}$ region. In this system, the $\mathrm{C}-\mathrm{O}$ stretching coordinates can be identified as very weak and broad band at $1153 \mathrm{~cm}^{-1}$ and others are not seen clearly.

Methylene deformation. The $\mathrm{CH}_{2}$ deformations of the ethylene bridge have been recognized to be sensitive to conformational properties of the cyclic system. Local symmetry coordinates of methylene include scissoring, wagging, twisting and rocking modes. The force constants of scissoring and wagging coordinates are rather analogous to each other between Left and Right species, so they would be shown with fairly narrow spectral feature. The scissoring mode is not identified clearly because it is inherently weak. However, the wagging mode is markedly seen at 1367 and $1384 \mathrm{~cm}^{-1}$ with huge intensity and relatively narrow width. The $\mathrm{Li}^{+}$ion complex of 18 -crown- 6 in the gas phase, recently reported using mass-selected infrared multiphoton dissociation spectroscopy, did not exhibit its wagging mode with any noticeable intensity. In our system, the recursive angular twisting along ethylene bridge (O-C-C-O) would occur during conformational adjustment upon restless relocation of $\mathrm{Li}^{+}$ion inside the cavity. Therefore it could build up the wagging dipole change because it could be combined in the in-phase manner with the torsion motion along $\mathrm{C}$ - $\mathrm{C}$ bridge, and moreover added up in the out-of-phase manner with the other part of ethylene bridge. (see dihedral angles in Table 1) The twisting and rocking modes are supposed not to appear due to instability of force constants from dihedral angle fluctuations.

In-plane deformation. Most modes corresponding to in-plane bending of pyridyl and benzo ring are expected to show a broad feature or not to be seen. The C-O-C bending of central ether linkage is supposed not to appear. This bending motion is highly associated with torsion mode of the ethylene bridge. Therefore it is not likely to be seen clearly as reported in recent study of $\mathrm{Li}^{+}$ion complex with 18-Crown-6. ${ }^{3}$ The benzo ring $\mathrm{C} \sim \mathrm{C} \sim \mathrm{C}$ deformation modes are supposed to appear at around $850 \mathrm{~cm}^{-1}$ region and not noticeably observed. The ring $\mathrm{C} \sim \mathrm{N} \sim \mathrm{C}$ deformation mode of pyridine ring is associated to a broad band at $\sim 630 \mathrm{~cm}^{-1}$.

Out-of-plane deformation and torsion. The C-H out-of-plane modes of the pyridyl group show steady force constants for three geometries, so it is expected to give a narrow band. A sharp band at $792 \mathrm{~cm}^{-1}$ is assigned to this mode. It comes with broadened moderate wings, which are attributed to the $\mathrm{C}-\mathrm{H}$ out-of-plane modes of benzo groups. The N-H out-of-plane modes are assigned to a band at $665 \mathrm{~cm}^{-1}$. The torsion modes of pyridyl and benzo ring system are anticipated to appear with broadening, but the ether and amide groups would not. Strong broad bands at 426 and $470 \mathrm{~cm}^{-1}$ region are attributed to the $\mathrm{C} \sim \mathrm{C}$ ring torsion.

\section{Conclusions}

Though $\mathrm{Li}^{+}$ion complex of 18-crown- 6 was presumed to hold a stable conformation of $S_{6}$ cage-like barrel structure, ${ }^{1}$ folded $D_{2}$ conformation of tight cage-shape around the cation was proposed to be more stable in the recent study. ${ }^{3}$ This proposition would be feasible in the case of plenty of flexibility in the

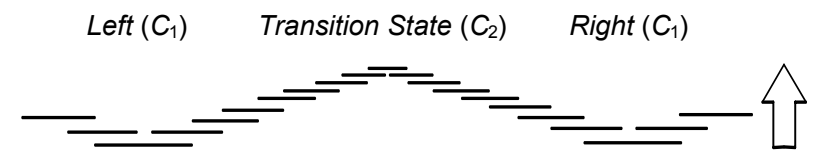

Scheme 2

cyclic system. Then, the infrared absorption is likely to show less broadening or coalescence in the spectral features. ${ }^{19}$ However, our complex system has much restricted motion of freedom and less flexibility in the cyclic system, and also less varieties of symmetry in the whole complex structure (possible only $C_{1} \rightleftarrows C_{2}$ ).

The density functional calculation at the level of BP86/ 6-31+ $\mathrm{G}^{* *}$ shows that $\mathrm{Li}^{+}$ion is trapped and rather free to move around inside the cavity, as much as about $0.70 \AA$. Through the relocation of $\mathrm{Li}^{+}$ion inside the cavity, the conformational changes would occur rapidly in the molecular structure of complex, as shown above Scheme 1, Left $\left(C_{1}\right) \rightleftarrows$ Transition State $\left(C_{2}\right) \rightleftarrows \operatorname{Right}\left(C_{1}\right)$. The potential barrier is merely $\sim 2.2 \mathrm{~kJ} / \mathrm{mol}$ for $C_{1} \rightarrow C_{2}$ conversion and vice versa, which is less than the thermal energy unit $k_{B} \mathrm{~T} \approx 2.5 \mathrm{~kJ} / \mathrm{mol}$ at ambient temperature. This may be illustrated as shown in Scheme 2 above. The length of each bar represents the relative lifetime of each state, and the arrow the relative energy state of each state.

During this structural alteration, the amide backbone turns its dihedral angle side to side about $\pm 3^{\circ}$, which would give an explanation for anomalous broadening. The central parts (pyridyl and ether linkage) except two benzo groups are twisting rapidly back and forth accompanied with weak torsions of two amide backbones. The whole structure can be illustrated just like a continuously twisting drum (or barrel) with two not-moving fixed small wings. Simultaneously, the intra-molecular electronic rearrangement (or exchange) would occur on the center parts. ${ }^{10-13}$ Some systems such as dipyridinium or radical aromatic anions showed enhanced infrared absorption where the intramolecular electron redistribution was counted as a major factor. ${ }^{21}$ In our case, it could be taken into account primarily that dynamic effects from conformational changes inside a barrel are responsible for the spectral features observed experimentally. Accordingly, those effects are spectrally exhibited, in particular, on $\mathrm{C}=\mathrm{O}$ and $\mathrm{N}-\mathrm{H}$ stretching bands which shows anomalous broadening nearly $\sim 150 \mathrm{~cm}^{-1}$, half width at half height.

Selected vibrational modes of stretching, in-plane/out-ofplane and methylene deformation, and torsion motion were interpreted in terms of the force constants variations of local symmetry coordinates for three conformers of the complex. The $\mathrm{C}-\mathrm{H}$ stretching mode and wagging mode of $\mathrm{CH}_{2}$ moiety in the ethylene bridge showed their enhanced intensity with relatively narrow bandwidth. Bending mode of C-O-C in ether linkage, various torsions and in-plane/out-of-plane modes were not seen or broadened. In conclusion, we have shown that the force constant variations could be applied to interpret the experimental infrared spectrum of $\mathrm{Li}^{+}$ion complex showing uncharacteristic features, otherwise hardly appreciate it.

Acknowledgments. This work was supported by the research grant of the Chungbuk National University in 2008. 


\section{References}

1. Glendening, E. D.; Feller, D.; Thompson, M. A. J. Am. Chem. Soc. 1994, 116, 10657.

2. (a) Brzezinski, B.; Schroeder, G.; Rabold, A.; Zundel, G. J. Phys. Chem. 1995, 99, 8519. (b) Zundel, G. J. Mol. Struct. 1999, 511, 19.

(C) Tsukube, H.; Shinoda, S.; Mizutani, Y.; Okano, M.; Takagi, K.; Hori, K. Tetrahedron 1977, 53, 3487.

3. Martinez-Haya, B.; Hurtado, P.; Hortal, A. R.; Hamad, S.; Steill, J. D.; Oomens, J. J. Phys. Chem. A 2010, 114, 7048.

4. Corvis, Y.; Korchowiec, B.; Korchowiec, J.; Badis, M.; MironiukPuchalska, E.; Fokt, I.; Priebe, W.; Rogalska, E. J. Phys. Chem. B 2008, 112, 10953.

5. Pigot, T.; Duriez, M.-C.; Cazaux, L.; Picard, C.; Tisnes, P. J. Chem. Soc., Perkin Trans. 2 1993, 221.

6. Khan, F. A.; Parasuraman, K.; Sadhu, K. K. Chem. Commun. 2009, 2399.

7. Kim, K.; Lee, H. J.; Choe, J.-I. Bull. Korean Chem. Soc. 2005, 26 , 645.

8. Shin, K.-H.; Shin, E. J. Bull. Korean Chem. Soc. 2009, 30, 1401.

9. Al-Rusaese, S.; Al-Kahtani, A. A.; El-Azhary, A. A. J. Phys. Chem. A 2006, 110, 8676.

10. Rocha, R. C.; Shreve, A. P. Inorg. Chem. 2004, 43, 2231.

11. Ito, T.; Hamaguchi, T.; Nagino, H.; Yamaguchi, T.; Washington, J.; Kubiak, C. P. Science 1997, 277, 660.
12. (a) Londergan, C. H.; Salsman, J. C.; Ronco, S.; Dolkas, L. M.; Kubiak, C. P. J. Am. Chem. Soc. 2002, 124, 6236. (b) Londergan, C. H.; Salsman, J. C.; Ronco, S.; Kubiak, C. P. Inorg. Chem. 2003, $42,26$.

13. Salsman, J. C.; Ronco, S.; Londergan, C. H.; Kubiak, C. P. Inorg. Chem. 2006, 45, 547.

14. Park, S.-K.; Min, K.-C.; Lee, C.; Hong, S. K.; Kim, Y.; Lee, N.-S. Bull. Korean Chem. Soc. 2009, 30, 2595.

15. (a) Kim, D. W.; Shin, Y. K.; Kim, C. S.; Oh, J. J.; Jeon, Y. S.; Kim, T. S. J. Korean Chem. Soc. 1992, 36, 669. (b) Kim, D. W.; Kim, C. S.; Choi, K. Y.; Jeon, Y. S. J. Korean Chem. Soc. 1993, 37, 491.

16. Kim, D. W.; Shin, Y. K.; Oh, J. J.; Kim, C. S.; Yang, J. Bull. Korean Chem. Soc. 1991, 12, 591.

17. Min, K.-C. Master Thesis; Chungbuk National University: Korea, 2002.

18. Matsuura, H.; Fukuhara, K.; Kaneko, K.; Yoshida, H. J. Mol. Struct. 1992, 265, 269.

19. (a) Chujo, T.; Saraoka, I.; Kato, S.; Sato, H.; Fukuhara, K.; Matsuura, H. J. Incl. Phenom. 1995, 22, 41. (b) Saraoka, I.; Kato, S.; Chujo, T.; Sato, H.; Fukuhara, K.; Matsuura, H. J. Incl. Phenom. 1995, 22, 59.

20. Takemura, H.; Sako, K. Tetrahedron Lett. 2005, 46, 8169.

21. (a) Brienne, S. H. R.; Boyd, P. D. W.; Schwerdtfeger, P.; Bowmaker, G. A.; Cooney, R. P. J. Chem. Soc. Faraday Trans. 1993, 89, 3015. (b) Brienne, S. H. R.; Cooney, R. P.; Bowmaker, G. A. J. Chem. Soc. Faraday Trans. 1991, 87, 1355. 